\title{
Amyloid Inspired Self-Assembled Peptide Nanofibers
}

\author{
Goksu Cinar, ${ }^{\dagger}$ Hakan Ceylan, ${ }^{\dagger}$ Mustafa Urel, ${ }^{\dagger}$ Turan S. Erkal, ${ }^{\dagger}$ E. Deniz Tekin, ${ }^{*},{ }^{\dagger}$ Ayse B. Tekinay, ${ }^{*}{ }^{\dagger}$ \\ Aykutlu Dâna, ${ }^{* \dagger}$ and Mustafa O. Guler*,† \\ ${ }^{\dagger}$ Institute of Materials Science and Nanotechnology, National Nanotechnology Research Center (UNAM), Bilkent University, \\ Ankara, Turkey, 06800 \\ ${ }^{\ddagger}$ Faculty of Engineering, University of Turkish Aeronautical Association, Ankara, Turkey, 06790
}

\section{Supporting Information}

ABSTRACT: Amyloid peptides are important components in many degenerative diseases as well as in maintaining cellular metabolism. Their unique stable structure provides new insights in developing new materials. Designing bioinspired selfassembling peptides is essential to generate new forms of hierarchical nanostructures. Here we present oppositely charged amyloid inspired peptides (AIPs), which rapidly self-assemble into nanofibers at $\mathrm{pH} 7$ upon mixing in water caused by noncovalent interactions. Mechanical properties of the gels formed by selfassembled AIP nanofibers were analyzed with oscillatory rheology. AIP gels exhibited strong mechanical characteristics superior to gels formed by self-assembly

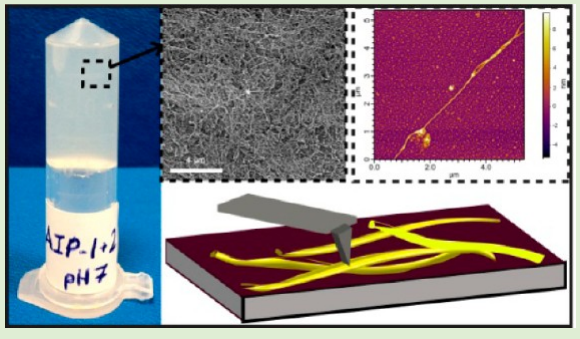
of previously reported synthetic short peptides. Rheological studies of gels composed of oppositely charged mixed AIP molecules (AIP-1 +2) revealed superior mechanical stability compared to individual peptide networks (AIP-1 and AIP-2) formed by neutralization of net charges through pH change. Adhesion and elasticity properties of AIP mixed nanofibers and charge neutralized AIP-1, AIP-2 nanofibers were analyzed by high resolution forcedistance mapping using atomic force microscopy (AFM). Nanomechanical characterization of self-assembled AIP-1 + 2, AIP-1, and AIP-2 nanofibers also confirmed macroscopic rheology results, and mechanical stability of AIP mixed nanofibers was higher compared to individual AIP-1 and AIP-2 nanofibers self-assembled at acidic and basic pH, respectively. Experimental results were supported with molecular dynamics simulations by considering potential noncovalent interactions between the amino acid residues and possible aggregate forms. In addition, HUVEC cells were cultured on AIP mixed nanofibers at $\mathrm{pH} 7$ and biocompatibility and collagen mimetic scaffold properties of the nanofibrous system were observed. Encapsulation of a zwitterionic dye (rhodamine B) within AIP nanofiber network was accomplished at physiological conditions to demonstrate that this network can be utilized for inclusion of soluble factors as a scaffold for cell culture studies.

\section{INTRODUCTION}

Amyloids contain nanostructures formed by peptides and proteins. ${ }^{1}$ Structural properties and aggregation kinetics of amyloids are intriguing because of their association with neurodegenerative diseases including Alzheimer's disease and Parkinson's disease. ${ }^{2,3}$ Amyloid structures are rich in $\beta$-sheet fibrils in which repetitive hydrogen bonding extends along the length of the fibrils. ${ }^{4}$ Compared to other natural proteinaceous materials such as silk, collagen, and keratin, self-assembled amyloid fibers show high stiffness and rigidity so that Young's modulus $(E)$ of the nanofibers can reach up to $10 \mathrm{GPa}^{1}$ Characterizations of these amyloid structures with converging approaches are crucial to understanding their complex selfassembly mechanism ${ }^{5}$ and the reasons behind their strong mechanical properties. ${ }^{6}$ Accumulating reports on amyloid formation point that stability of the structures mainly depends on cross $\beta$-arrangements of the fibers. ${ }^{7}$ Hydrophobic and hydrogen bonding interactions between the peptides are important for stability of cross $\beta$-arrangements. In addition, $\pi-\pi$ interactions between phenylalanine residues and electrostatic interactions between charged residues such as glutamic acid and lysine contribute to the stability of the amyloid fibers. ${ }^{8}$
Besides molecular analysis of fiber formation, mechanical characterization of these structures is extremely important to reveal the source of their rigid and stable existence. Nanomechanical properties of many amyloid structures such as $\alpha$-synuclein, ${ }^{9} \mathrm{~A} \beta$ (1-40) amyloid fibril, ${ }^{10}$ and insulin ${ }^{11}$ amyloid fibrils were previously studied by using atomic force microscopy (AFM) and nanoscale mechanical characterizations provided valuable information about fibril strength, adhesive properties, and stiffness of the amyloid structures. ${ }^{12}$ In-depth knowledge on materials inspired from peptides aid researchers in designing artificial proteinaceous nanostructures for practical applications ${ }^{1,13}$ such as gene delivery, ${ }^{14}$ drug release, ${ }^{15}$ catalytic activity, ${ }^{16}$ and tissue engineering. ${ }^{17}$ Peptides synthetically built by amino acids have a great potential for developing functional materials due to their unique structures, simplicity, and biocompatibility. ${ }^{18}$ Synthetic design of peptides enables us to form desired conformations and appealing supramolecular structures via the self-assembly process. ${ }^{19,20}$

Received: July 20, 2012

Revised: September 16, 2012

Published: September 17, 2012 
a
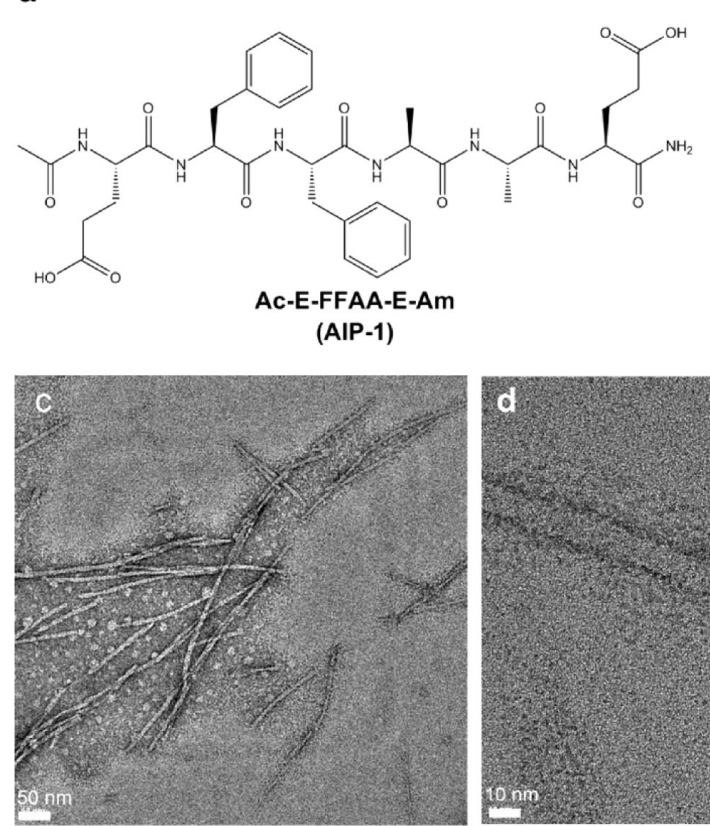

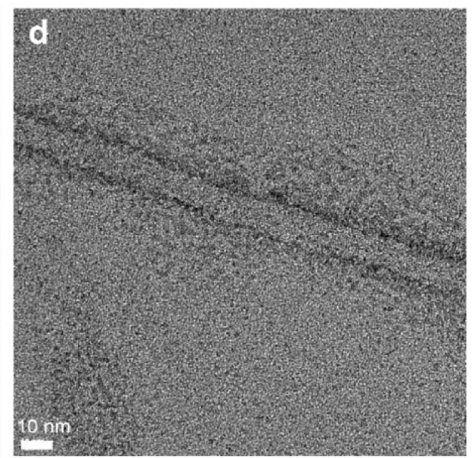

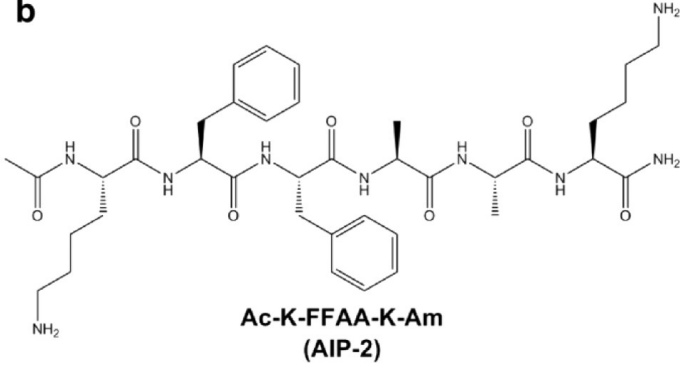

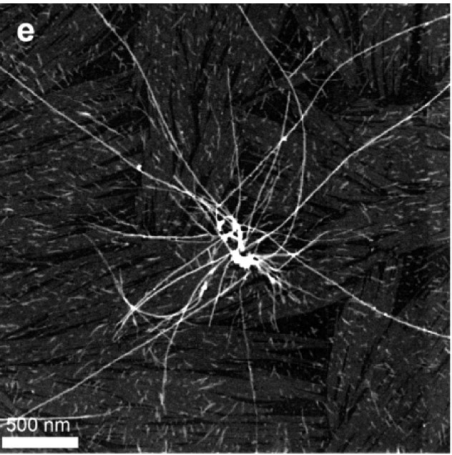

Figure 1. Chemical representation of AIP-1 (a) and AIP-2 (b) peptides. (c, d) TEM images of AIP-1 + 2 nanofibers (scale bar 50 and $10 \mathrm{~nm}$ ). (e) STEM image of AIP-1 + 2 peptide nanofibers and their amyloid like nucleation characteristics (scale bar, $500 \mathrm{~nm}$ ).

In this study, we designed and synthesized oppositely charged short amyloid-inspired peptide sequences: Ac-EFFAAE-Am (AIP-1) and Ac-KFFAAK-Am (AIP-2; Figure 1a,b) that selfassemble into amyloid like nanofibers upon mixing at $\mathrm{pH} 7$ in water. Noncovalent interactions and characteristic motifs that are inspired by amyloid protein aggregations were exploited in our design. ${ }^{21}$ By using charged Glu and Lys residues at the $\mathrm{N}$ and $\mathrm{C}$ terminals of the peptides, we increased the electrostatic interactions between peptides and controlled self-assembly process via manipulation of charges. Furthermore, the hydrophobic segment of the AIP-1 and AIP-2 supported aggregation by hydrophobic $^{22}$ and $\pi-\pi$ interactions, ${ }^{23}$ which are commonly found in amyloid structures. ${ }^{24}$ Repetitive H-bonding along the fibril structures led to formation of stable nanofibers. A combination of these noncovalent interactions in our design resulted in formation of self-assembled peptide nanofibers (Figure 1c,d) and the molecules revealed amyloid-like structural nucleation characteristics $^{5,25,26}$ (Figure 1e). In addition to the smart design strategy of the peptides, we performed molecular dynamics simulations to understand the self-assembly mechanism of oppositely charged peptides and noncovalent interactions taking place during aggregation. The simulations provided a dynamic model of aggregation kinetics and revealed a $\beta$-sheet rich formation in the assembly process. Amyloid-inspired design strategy also provided sol-gel conversion to obtain self-supporting peptide gels. Gels formed by mixing AIP-1 and AIP-2 at $\mathrm{pH} 7$ in water showed remarkable mechanical properties without addition of any cross-linking reagents and inorganic materials. ${ }^{27}$ In addition to bulk mechanical properties, we performed nanomechanical characterizations to map adhesive forces and elasticity of the self-assembled nanofibers formed by mixing AIP molecules $($ AIP-1 +2$)$ at neutral $\mathrm{pH}$ to understand the relationship between mechanical properties and the self-assembly mechanism. We also tested amyloid-inspired nanostructures as a synthetic extracellular scaffold system. Cell-matrix interactions were studied by culturing human umbilical vein endothelial cells (HUVECs) on the peptide nanofibers. Analysis of cell behavior on these scaffolds revealed great potential for cell culture applications even in the absence of any known biological signals. In addition, encapsulation of a zwitterionic dye within the gels of selfassembled AIP-1 + 2 nanofibers showed high encapsulation capacity. Thus, the gels can be utilized to deliver biologics and small molecule drugs for medical applications.

\section{EXPERIMENTAL SECTION}

Peptide Synthesis. Amyloid-inspired peptides were synthesized using solid phase 9-fluorenylmethoxycarbonyl (Fmoc) peptide synthesis method. ${ }^{28}$ The synthesis of $0.5 \mathrm{mmol}$ AIP-1 (Ac-EFFAAE-Am) and AIP-2 (Ac-KFFAAK-Am) peptides were carried out by amino acid coupling with 2 mol equiv of Fmoc protected amino acid, $1.95 \mathrm{~mol}$ equiv of $O$-benzotriazole- $N, N, N^{\prime}, N^{\prime}$-tetramethyl-uronium-hexafluorophosphate (HBTU), and $3 \mathrm{~mol}$ equiv of $N, N$-disopropylethylamine (DIEA) for $2 \mathrm{~h}$. MBHA rink amide resin was used to construct the peptides on solid support. Removal of Fmoc protecting group on amino acids was accomplished by $20 \%$ piperidine/DMF solution for $25 \mathrm{~min}$. Cleavage of the peptides from resin was carried out with a mixture of TFA/TIS/water in a ratio of 95:2.5:2.5 for $3 \mathrm{~h}$. Excess TFA and organic solvents were removed by rotary evaporation. Then peptide was precipitated using diethyl ether at $-20{ }^{\circ} \mathrm{C}$ overnight. Precipitate was collected by centrifugation. White peptide precipitate was dissolved in water and frozen at $-80{ }^{\circ} \mathrm{C}$. The frozen sample was freeze-dried for three days. AIP-2 peptide was dissolved in $1 \mathrm{mM} \mathrm{HCl}$ solution and then freeze-dried again to remove residual TFA.

Liquid Chromatography and Mass Spectrometry (LC-MS). A total of $1 \mathrm{mg} / \mathrm{mL}$ AIP-1 was prepared for LC-MS analysis. The identity and purity of the peptide was assessed by using Agilent 65301200 QTOF LC-MS with electrospray ionization source (ESI) equipped with a Zorbax Extend C18 column (Agilent 4.6, $100 \mathrm{~mm}$, $3.5 \mathrm{~mm}$ ). Gradient of A, $0.1 \%$ ammonium hydroxide in water, and B, $0.1 \%$ ammonium hydroxide in acetonitrile, was used in LC-MS. A total of $1 \mathrm{mg} / \mathrm{mL}$ AIP-2 was analyzed by Agilent Zorbax SB-C18 column (rapid resolution HT $\left.2.150 \mathrm{~mm}^{2}, 1.8 \mu \mathrm{m}\right)$ in gradient of water $(0.1 \%$ formic acid) and acetonitrile ( $0.1 \%$ formic acid). The purity of the peptides was determined to be higher than 95\% (Figure S1).

Scanning Electron Microscopy (SEM). Sample was prepared by addition of $50 \mu \mathrm{L}$ of 4,3 , or $2 \%$ (w/v) AIP- 1 to $50 \mu \mathrm{L}$ of 4,3 , or $2 \%(\mathrm{w} / \mathrm{v})$ AIP-2 on metal mesh. The samples were kept at room 
temperature for $15 \mathrm{~min}$ for gel formation, and then distilled water in the gel was replaced by a series of ethanol (40,60, 80, and 100\%). Gel was dried with a critical point dryer and coated with $8 \mathrm{~nm} \mathrm{Au} / \mathrm{Pd}$. FEI Quanta 200 FEG scanning electron microscope equipped with ETD detector was used for imaging.

Transmission Electron Microscopy (TEM). A FEI Tecnai G2 F30 TEM instrument was employed. Briefly, $2.5 \mu \mathrm{L}$ of AIP-1 and -2 solutions were mixed for gel formation. The mixture was incubated for $15 \mathrm{~min}$. Then, the gel was diluted in 1:10 ratio by addition of $45 \mu \mathrm{L}$ of water. A diluted sample was mixed very slowly. A total of $5 \mu \mathrm{L}$ of diluted sample was casted onto TEM grid very carefully and the sample was kept on the grid for $5 \mathrm{~min}$. Then, excess sample was removed from the surface of the grid by micropipets. Negative staining was performed using $2 \%(\mathrm{w} / \mathrm{v})$ uranyl acetate.

Molecular Dynamics Simulation. The peptides were prepared using Argus Lab ${ }^{29}$ with an ideal backbone geometry of a beta strand $\left(\varphi=-120^{\circ}, \psi=120^{\circ}\right)$. Then, five AIP-1 and -2 molecules were put randomly in a cubic box of size $690 \mathrm{~nm} .{ }^{30}$ The minimum distance between the solute and the box was set to $1.0 \mathrm{~nm}$. The system was solvated with 22541 explicit water molecules. Counterions $\left(\mathrm{Na}^{+}, \mathrm{Cl}^{-}\right)$ were added to neutralize the system. After the system was prepared, energy of the system was minimized via steepest-descent method to get the appropriate structure. Then, the resulting energy-minimized system was equilibrated with 100 ps of NVT and 100 ps of NPT using position restraints. This procedure was followed by molecular dynamics (MD) production run to generate trajectory data for analysis. Atomistic MD simulations were performed with GROMACS $\operatorname{code}^{30}$ with GROMOS96 $53 \mathrm{a}^{31}$ united atom force field for the peptides and SPC (simple point charge) ${ }^{32}$ force field for water. Leap-frog algorithm ${ }^{33}$ was used for integration of Newton's equation of motion. Time step for MD integrator was set to $2 \mathrm{fs}$ and all bond lengths were constrained using linear constraint solver (LINCS) algorithm. ${ }^{34}$ Simulations were carried out using periodic boundary conditions in all directions. Particle mesh ewald (PME) algorithm ${ }^{35,36}$ was used to calculate the long-range electrostatic interaction with a grid spacing of $0.16 \mathrm{~nm}$ and a fourth order cubic interpolation. Short range electrostatic and van der Waals interactions were cut off at 1.0 $\mathrm{nm}$ radius. An isotropic Parrinello-Rahman barostat ${ }^{37}$ was applied to keep the pressure constant at 1 bar with a coupling time constant of $2.0 \mathrm{ps}$ and using an isothermal compressibility of $4.5 \times 10^{-4} \mathrm{bar}^{-1}$. To keep the temperature constant at $300 \mathrm{~K}$, the system was coupled to a velocity rescaling thermostat ${ }^{38}$ with a coupling time constant of $0.1 \mathrm{ps}$. Initial velocities were generated randomly from Maxwell distribution at $300 \mathrm{~K}$. The snapshots were made with the visual molecular dynamics (VMD) software. ${ }^{39}$ The simulations were carried out for $70 \mathrm{~ns}$.

FT-IR Analysis. Various concentrations (4, 3, 2, 1\% (w/v)) of AIP-1 +2 gels were prepared separately at $\mathrm{pH} 7$. The gels formed on Petri dishes were instantly frozen in liquid nitrogen to preserve their architectural integrity. Frozen gels were then kept at $-80^{\circ} \mathrm{C}$ overnight. They were freeze-dried after dehydration. Dried gels were weighed and mixed with $\mathrm{KBr}$ powder with a ratio of $100 \mathrm{mg} \mathrm{KBr} / 1 \mathrm{mg}$ dried sample. Mixtures containing $\mathrm{KBr}$ and peptide samples were homogenized to press and form $\mathrm{KBr}$ pellets. Absorbance analysis of the samples was carried out with Bruker VERTEX 70 with Hyperion scanning microscope, where wavenumber was determined between 300 and $4000 \mathrm{~cm}^{-1}$.

Circular Dichroism (CD). From 1\% (w/v) solution of AIP-1 and -2 $(0.0135 \mathrm{M}), 30 \mu \mathrm{L}$ of AIP-1 and -2 were diluted up to $600 \mu \mathrm{L}$, separately. Diluted solutions $(0.34 \mathrm{mM})$ were mixed with $1: 1$ ratio $(150 \mu \mathrm{L}$ of AIP- $1+150 \mu \mathrm{L}$ of AIP- 2$)$ and the final peptide concentration was $0.34 \mathrm{mM}(0.025 \%(\mathrm{w} / \mathrm{v}))$. Jasco J-815 CD spectrophotometer was used for $\mathrm{CD}$ analysis. Samples were measured between 300 and $190 \mathrm{~nm}$ with data pitch, $0.1 \mathrm{~nm}$; sensitivity, standard; D.I.T., $4 \mathrm{~s}$; bandwidth, $1 \mathrm{~nm}$; scanning speed, $100 \mathrm{~nm} / \mathrm{min}$.

Congo Red Staining. The $5 \times 10^{-3} \mathrm{M}$ Congo red solution was prepared by addition of $14 \mathrm{mg}$ of Congo red powder into $4 \mathrm{~mL}$ of water. The mixture was filtered with $0.2 \mu \mathrm{m}$ filter and $\mathrm{pH}$ of the dye solution was arranged to around $\mathrm{pH} 7$. For sample preparation, $1 \mu \mathrm{L}$ of $4 \%(\mathrm{w} / \mathrm{v})$ AIP- 1 and $1 \mu \mathrm{L}$ of $4 \%(\mathrm{w} / \mathrm{v})$ AIP- 1 at $\mathrm{pH} 7$ were mixed. Gel formation was observed after $5 \mathrm{~min}$, and $2 \mu \mathrm{L}$ of $5 \times 10^{-3} \mathrm{M}$ Congo red solution at $\mathrm{pH} 7$ was added onto the gel. The mixture was gently mixed and incubated for $1 \mathrm{~h}$ for interaction of gel and dye. The control group of Congo red dye alone was also prepared. After an hour of incubation, mixtures were diluted up to $1 \mathrm{~mL}$. Final concentration of the peptides was $0.008 \%(\mathrm{w} / \mathrm{v})$ and Congo red concentration was decreased to $10 \mu \mathrm{M}$ in all samples. Spectramax M5 Microplate Reader was used for absorbance measurements.

Oscillatory Rheology. Rheology measurements of 4, 3, 2, 1, and $0.5 \%(\mathrm{w} / \mathrm{v})$ of AIP-1 $+2(1: 1)$ samples at $\mathrm{pH} 7$ were performed to understand the mechanical properties of the resulting gels. Total volumes of the samples were $250 \mu \mathrm{L}(125 \mu \mathrm{L}$ AIP- $1+125 \mu \mathrm{L}$ AIP-2 at neutral $\mathrm{pH}$ ) and during the analysis, PP25-SN17979 measuring device with $25 \mathrm{~mm}$ diameter was used. Measuring distance was determined as $0.5 \mathrm{~mm}$. Time sweep tests of each sample were carried out for $1 \mathrm{~h}$. Angular frequency and strain magnitudes were determined as $\omega=10$ $\mathrm{rad} / \mathrm{s}$ and $\gamma=0.1 \%$, respectively. Angular frequency was logarithmically ramped from $\omega=0.1$ to $100 \mathrm{rad} / \mathrm{s}$, during which strain was kept constant at $\gamma=0.1$, which is within the linear viscoelastic regime. Thixotropic tests of all samples were carried out with different conditions and angular frequency was kept constant at $\omega=10 \mathrm{rad} / \mathrm{s}$ at all points of data collection. For the first $5 \mathrm{~min}$ (in Linear Viscoelastic Regime, LVR), strain was set to a constant value, which was $\gamma=0.1 \%$. A total of 10 data points were collected in that regime every $30 \mathrm{~s}$. Then, the test was continued with high shear regime for damaging equilibrated gels. Shear rate was changed between $\gamma=0.1-1000 \%$ with logarithmic increase. Recovery of gels was analyzed by keeping shear rate at constant value; $\gamma=0.1$ (back to LVR) for $10 \mathrm{~min}$. Anton Paar MCR-301 rheometer was used for the analysis. Measurements were reported as average of three repeats.

Atomic Force Microscopy (AFM) and Nanomechanical Characterization. AFM sample preparation was performed by dilution of $4 \%(\mathrm{w} / \mathrm{v})$ AIP-1 +2 gel at $\mathrm{pH} 7$, AIP-1 gel at $\mathrm{pH} 5$, and AIP-2 gel at $\mathrm{pH} 10$ up to $0.05 \%(\mathrm{w} / \mathrm{v})$ solutions through water addition. Then, a drop of the diluted sample was put onto silicon wafer and kept at room temperature for drying. The system used in nanomechanical characterization was an improved version of a previous work. ${ }^{40}$ The method was further developed and optimized to measure a series of samples. During measurement, topography was taken in the first pass, and nanomechanical characterization was done on the second pass when the cantilever was lifted a few nanometers and the sample was oscillated instead of cantilever. Topography was measured in noncontact AFM mode. Sample oscillation signal was provided with a function generator (DS345, SRS) at $2 \mathrm{kHz}$ with nominally $5 \mathrm{~nm}$ indentation. Before the measurement, cantilever was calibrated on a silicon sample. The calibration procedure included measurement of the spring constant of cantilever, and transfer function for deflection to photodiode current response. A commercial microscope (MFP3D, Asylum Research) was used in the experiments. An auxiliary digitizing oscilloscope was used to capture the force-distance measurements. A custom program was used to process the obtained data. In extraction of the histograms of mechanical properties, each force-distance curve was divided into approach and retraction parts, and adhesion forces, applied maximum forces, and the contact slopes were calculated.

Cell Culturing and Maintenance. Human umbilical vein endothelial cells (HUVEC) were used to characterize cell-matrix interactions. HUVECs were donated by Yeditepe University, Istanbul, Turkey, and were purified as described. ${ }^{41}$ Purified cells were characterized by immunostaining with CD34, CD31, and CD90 surface markers. These cells were found to be positive for CD31 and CD34 but negative for CD90. During maintenance, cells were cultured in 75 $\mathrm{cm}^{2}$ polystyrene cell culture flasks with $10 \%$ fetal bovine serum (FBS), $2 \mathrm{mM}$ L-glutamine, and $1 \%$ penicillin/streptomycin containing Dulbecco's modified Eagle medium (DMEM). All tests and splitting were carried out at $80-90 \%$ confluency using trypsin/EDTA chemistry. Cells were diluted 1:2 and 1:3 for splitting.

Adhesion, Spreading, Viability, and Morphological Analyses of HUVECs. Samples of peptide nanofibers for in vitro experiments were prepared in situ on cover glass surfaces. Briefly, $50 \mu \mathrm{L}$ AIP- 1 and $50 \mu \mathrm{L}$ AIP- 2 at $0.2 \%(\mathrm{w} / \mathrm{v})$ concentrations were mixed on glass coverslips to form nanofibers. The coatings were then dried in a chemical 

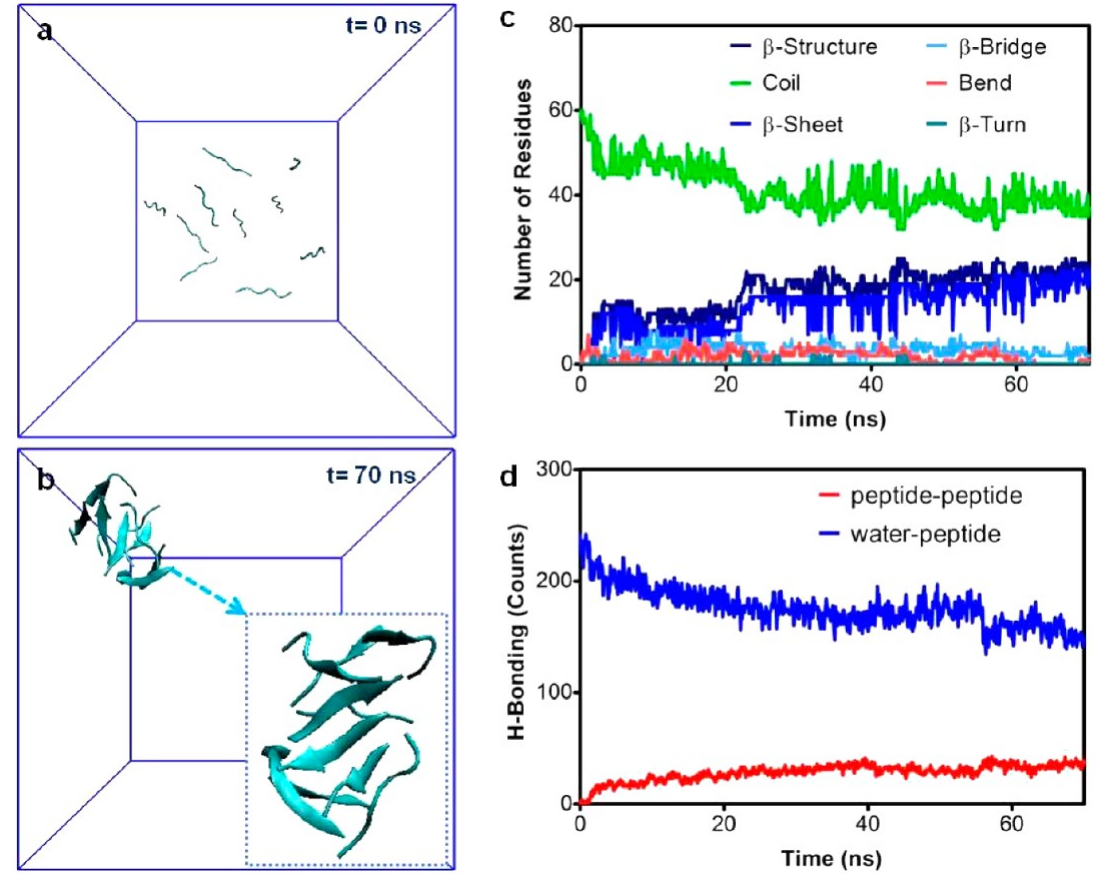

Figure 2. (a, b) Snapshots obtained from Molecular Dynamics simulations revealed aggregation of the AIP-1 and -2 peptides (0-70 ns); (c) Change in secondary structures of the peptides with respect to time; (d) Change in H-bonding (counts) between peptide-peptide and water-peptide molecules during the simulation period of $70 \mathrm{~ns}$.

hood overnight. Sterilization of the coatings was achieved under UV illumination for $1 \mathrm{~h}$. The coatings were washed with phosphate buffered saline (PBS) to remove any unbound residue. Peptide-coated surfaces were incubated with cells under standard cell culture conditions $\left(37^{\circ} \mathrm{C}, 5 \% \mathrm{CO}_{2}\right)$ for $24 \mathrm{~h}$ and were investigated by SEM. A nanofibrous layer on surfaces was clearly identified (Figure S16). Collagen I coated glass surfaces served as positive control. Cell adhesion test was performed in a similar manner as previously reported. ${ }^{42}$ Prior to cell seeding, cells were treated with serum-free DMEM supplemented with $0.05 \%(\mathrm{w} / \mathrm{v})$ cyclohexamide and $4 \%(\mathrm{w} / \mathrm{v})$ bovine serum albumin (BSA) for $1 \mathrm{~h}$. HUVECs were seeded at a density of $2 \times 10^{4}$ cells $/ \mathrm{cm}^{2}$. The test was limited to $2 \mathrm{~h}$. After $2 \mathrm{~h}$, unbound cells were washed with PBS. Adhered cells were fluorescently stained with Calcein AM. The number of adhered cells was quantified by imaging at least four random frames on each replicate with four replicates for each group. Morphology and spreading of HUVECs at $2 \mathrm{~h}$ were investigated by fluorescently labeling actin cytoskeleton with Phalloidin-TRITC. Cell nuclei were counterstained with TO-PRO-3 Iodide. Samples were inspected with a Zeiss LSM 510 confocal microscope. Cell diameter and area were measured on the confocal images using Image J software from NIH. For each group, at least eight random images were used (Figure S15). Viability of HUVECs on AIP$1+2$ nanofibers was investigated at $24 \mathrm{~h}$. HUVECs were seeded on the surfaces at a density of $5 \times 10^{3}$ cells $/ \mathrm{cm}^{2}$. After $24 \mathrm{~h}$, samples were washed with PBS to remove unbound cells. Adhered cells were fluorescently stained with Calcein AM. Quantification was done in the same way as the adhesion test. Morphology of cells at $24 \mathrm{~h}$ was investigated under confocal microscope. The staining procedure was the same as spreading analysis at $2 \mathrm{~h}$. To evaluate proliferation of HUVECs on peptide nanofibers, Click-iT EdU assay was employed. HUVECs were seeded on samples at a density of $2.5 \times 10^{3}$ cells $/ \mathrm{cm}^{2}$. A total of $12 \mathrm{~h}$ after seeding, cells were incubated with a nucleoside analog of thymine, EdU (5-ethynyl-2'-deoxyuridine), in cell culture media for another $48 \mathrm{~h}$. During $\mathrm{S}$ phase of the cell cycle, EdU incorporates into DNA and, hence, enables binding of Alexaflour-488 conjugated azide, as described in the manual sheet of the supplier.

Encapsulation of Rhodamine B. Stock solution of the dye was prepared as $1.252 \mathrm{mM}$ and was diluted to $0.125 \mathrm{mM}$ for encapsulation within gels. Calibration curve of rhodamine B (Rho B) was obtained by $128 \times$ dilution of the stock solution. For the encapsulation experiment, gels were prepared as 4,3 , and $2 \%(\mathrm{w} / \mathrm{v})$ mixture of AIP- 1 and AIP-2 at neutral $\mathrm{pH}$. Encapsulation of the dye was carried out during gelation of the peptide mixture. A total of $30 \mu \mathrm{L}$ of AIP- 2 and $10 \mu \mathrm{L}$ of $0.125 \mathrm{mM}$ dye were mixed in an eppendorf tube. For gelation, $30 \mu \mathrm{L}$ of AIP-1 was added into the system. Then, all peptide mixtures containing the dye were kept at room temperature for an hour to obtain stable systems $(n=3)$.

\section{RESULTS AND DISCUSSION}

Self-Assembly of AIP Molecules. Synthesis of designer amyloid-inspired AIP-1 and -2 were carried out by Fmoc solid phase synthesis method. Besides hydrophobic residues, AIP-1 and -2 contain two hydrophilic Lys and Glu residues, respectively, and the peptides have -2 and +2 net charges when they are dissolved in water at $\mathrm{pH}$ 7. These charged residues increase the solubility of the peptides and the peptides were soluble up to $4 \%(\mathrm{w} / \mathrm{v})$ concentration in water at $\mathrm{pH} 7$. Presence of net positive and negative charges on AIP-1 and -2, respectively, hindered self-assembly of these peptides separately. On the other hand, mixture of oppositely charged AIP-1 and -2 in water at $\mathrm{pH} 7$ led to rapid self-assembly resulting in nanofiber formation (Figures 1c-e and S2). Charge screening enabled amyloid inspired noncovalent interactions fiber elongation, such as hydrogen bonding, hydrophobic and $\pi-\pi$ interactions acted as a switch. The AIP- $1+2$ nanofibers physically entangled to form a three-dimensional network (Figure S4). As a result of encapsulation of water by the network, gelation took place instantly, depending on the initial concentration of the building blocks (Figure S3).

Simulation of Noncovalent Interactions and Secondary Structure Analysis of AIP Nanofibers. The self-assembly mechanism caused by noncovalent interactions ${ }^{8}$ was studied by molecular dynamics simulation. Figure $2 \mathrm{a}, \mathrm{b}$ includes two representative snapshots of $70 \mathrm{~ns}$ simulation created via visual molecular dynamics (VMD; Figure S5). Initial configuration of 

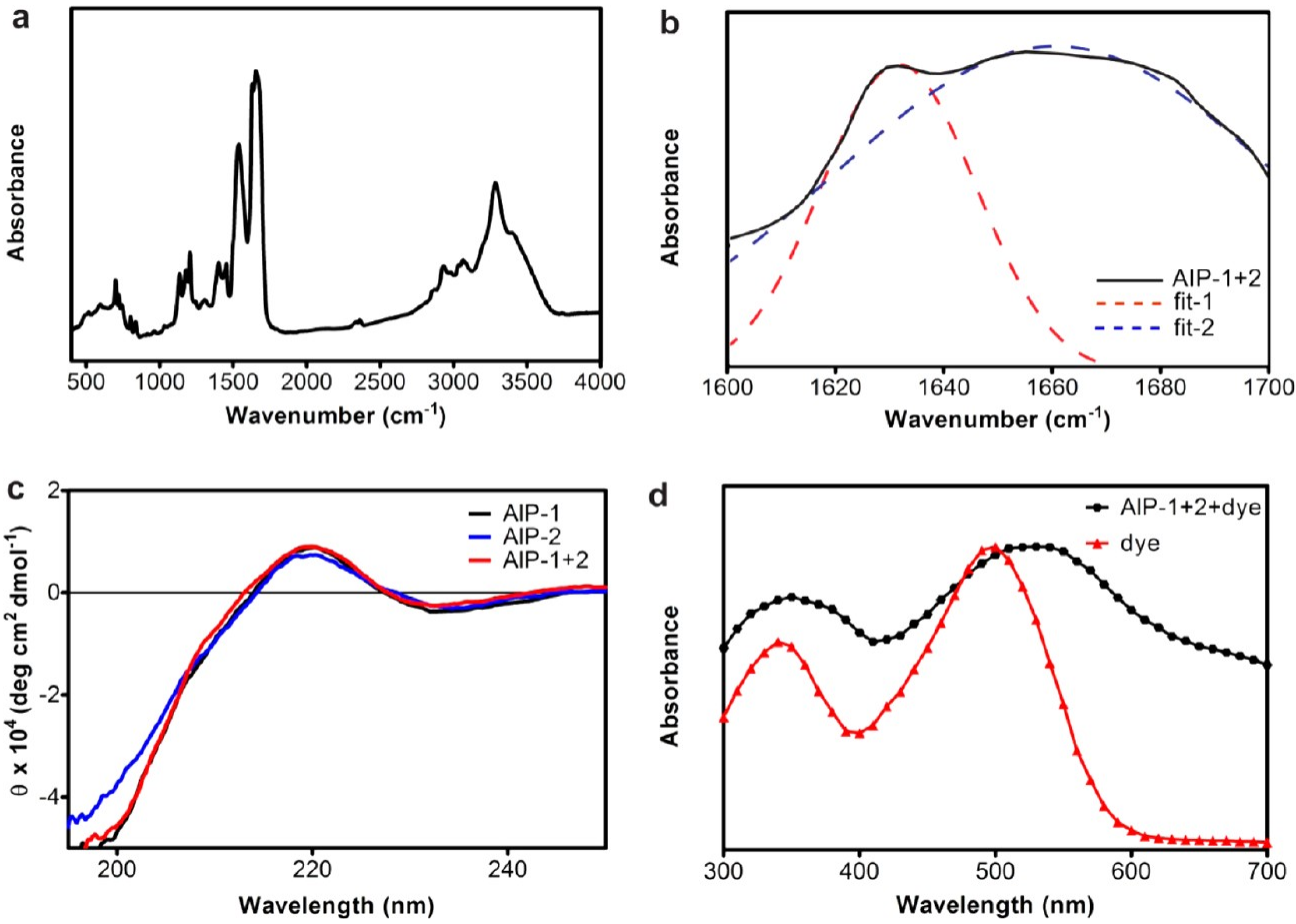

Figure 3. Secondary structure analysis of AIP-1 + 2 nanofibers with FT-IR: (a) large scale spectrum, (b) detailed analysis of amide I region (1600$1700 \mathrm{~cm}^{-1}$; - - Gaussian fittings), (c) molar ellipticity of AIP-1 +2 peptide nanofibers, (d) absorbance spectra of dye (Congo red) with and without AIP-1 + 2 .

randomly distributed peptides (of the random coil form) came together to form $\beta$-sheet structures. AIP-1 had a tendency to form a dimer with AIP-2 during the simulations, and same-type of peptides did not form dimers. At the end of the simulation, four dimers were formed out of five AIP-1 and five AIP-2 molecules and only one AIP- 1 and AIP- 2 molecule stayed out of the $\beta$-sheet structure. Thus, oppositely charged peptide dimerization was the first step of the aggregation. When total potential energy of the whole system over the simulation time was studied, final aggregated structure had the lowest energy conformation (Figure S6e). We further calculated the shortrange electrostatic energy between the Lys and Glu residues and plotted the change in energy during aggregation (Figure S6d). Electrostatic potential energy decreased over simulation time as peptides formed more stable $\beta$-sheet-rich aggregates. Dictionary of Secondary Structure of Proteins (DSSP) program by Kabsch and Sander ${ }^{43}$ was used for the secondary structure assessment of each peptide as a function of simulation time. DSSP analysis showed that the initial random coil structures turned into $\beta$-sheet rich secondary structure containing different forms of $\beta$-sheets (Figure 2c) and final secondary structure population at $70 \mathrm{~ns}$. Simulaton study revealed $60 \%$ of $\beta$-sheets, $30 \%$ of $\beta$-bridges, and $10 \%$ of mixture of random coil and $\beta$-bends (Figure S7). Because dimerization of the AIP-1 and -2 molecules was the first step of aggregation, as mentioned above, we analyzed the dimers carefully and observed that the secondary structures of the peptide components of a given dimer are identical. For instance, when AIP1 had some coil part, AIP-2 also had a coil part. In addition to structural analysis of the peptides during simulation, we also examined hydrogen bonds among the peptides and interactions between peptides and surrounding water molecules. When peptides started to form aggregates, the number of hydrogen bonds between peptides and water molecules began to decrease, while the number of hydrogen bonds among the peptides participating in $\beta$-sheets increased over time (Figure 2d). Hydrophobic and $\pi-\pi$ interactions, which were taken into account if the distance between the atoms of the residues was shorter than $0.4 \mathrm{~nm}$, played significant roles in the aggregation depending on the number of contact sites. Hydrophobic interactions were analyzed by looking at Phe and Ala residues, and $\pi-\pi$ interactions were analyzed between Phe residues. There was an increase in the number of contacts for both hydrophobic and $\pi-\pi$ interactions over time (Figure S6a,b). Solvent accessible surface area (SASA) of hydrophilic and hydrophobic segments was analyzed to determine the peptide aggregation. The hydrophilic SASA of the peptides decreased from $\approx 38 \mathrm{~nm}^{2}$ to $\approx 18 \mathrm{~nm}^{2}$ and the hydrophobic SASA decreased from $\approx 66 \mathrm{~nm}^{2}$ to $\approx 29 \mathrm{~nm}^{2}$ (Figure S6c). The decrease of the hydrophobic SASA was because of the aggregations. Hydrophilic SASA also decreased, however, the change in the hydrophobic SASA dominated.

FT-IR, circular dichroism (CD), and Congo red staining were carried out for secondary structure analysis of the selfassembled AIP-1 + 2 nanofibers. Amyloid forming peptides are known to aggregate as $\beta$-strands that are perpendicular to the fiber. ${ }^{4}$ FT-IR spectra of self-assembled AIP-1 + 2 nanofibers (Figures 3a and S8) showed a broad peak between 1600 and $1700 \mathrm{~cm}^{-1}$, which corresponds to the amide I band. ${ }^{44}$ Gaussian fitting in this range (Table S1) pointed two significant peaks at 1632 and $1662 \mathrm{~cm}^{-1}$ (Figure $3 \mathrm{~b}$ ). The $\mathrm{C}=\mathrm{O}$ stretching vibrations generate peaks in the amide I region around $1632 \mathrm{~cm}^{-1}$ associated with the $\beta$-sheet secondary structure. ${ }^{45,46}$ The presence of a $\beta$-turn secondary structure is observed at $1662 \mathrm{~cm}^{-1}$. ${ }^{46}$ Analysis of the AIP- $1+2$ peptide nanofibers with FT-IR showed that the network consisted of $\beta$-sheet rich secondary structure, which is in agreement with the simulation and DSSP analysis (Figures $2 \mathrm{~b}$ and S7). On the other hand, CD 
a
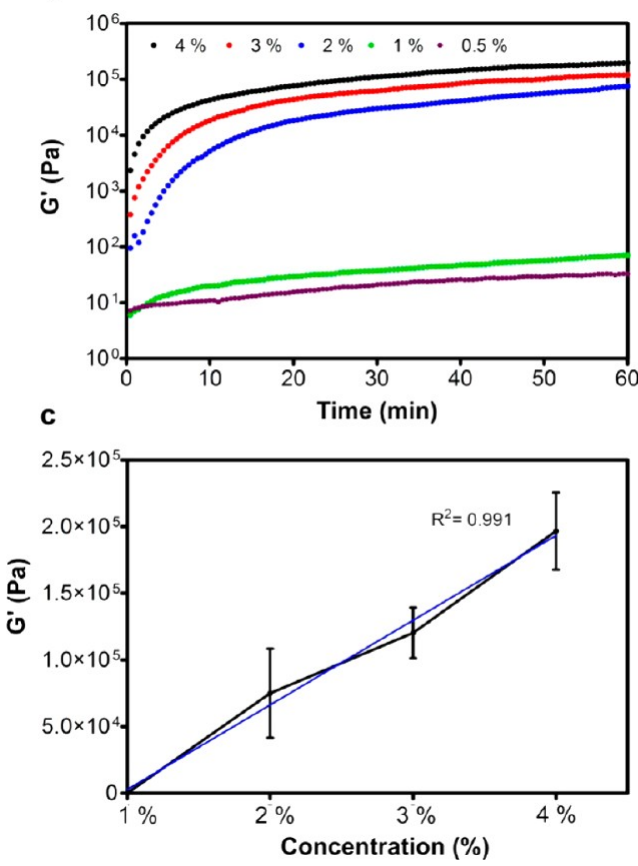

b

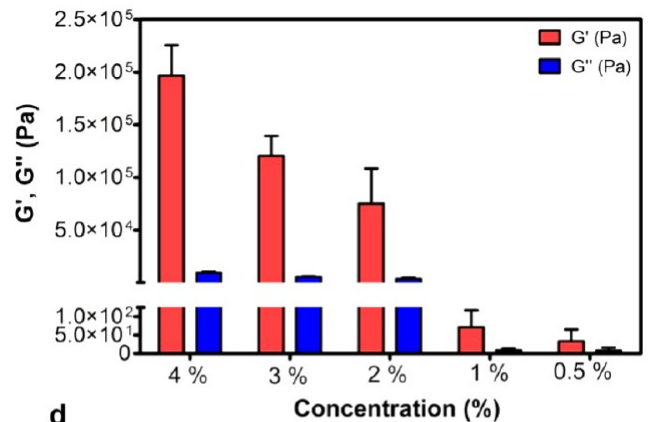

d

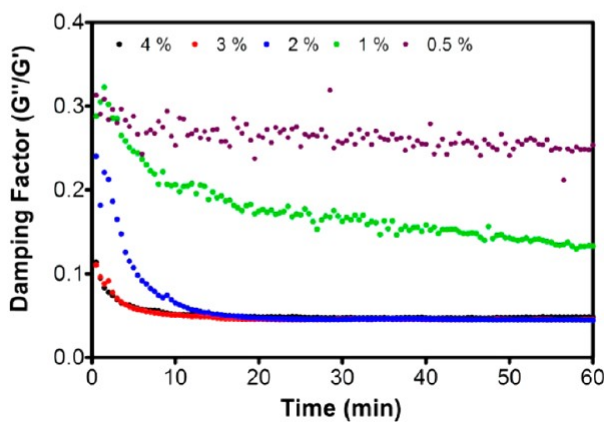

Figure 4. (a) Storage modulus $\left(G^{\prime}\right)$ change at different concentrations of AIP- $1+2$ gels at $\mathrm{pH} 7$ at 60 min, under constant strain $(0.1 \%)$ and angular frequency $(10 \mathrm{rad} / \mathrm{s})$; (b) Equilibrium storage and loss modulus $\left(G^{\prime}, G^{\prime \prime}\right)$ of AIP-1 +2 peptide gels at $\mathrm{pH} 7$; (c) Linear dependence of storage modulus of AIP-1 +2 peptide gels to concentration change at $\mathrm{pH} 7$; (d) Damping factor $\left(G^{\prime \prime} / G^{\prime}\right)$ change of different concentrations of AIP-1 +2 gels at $\mathrm{pH} 7$ for $60 \mathrm{~min}$.

spectrum of AIP-1 +2 showed red-shift relative to typical $\beta$-sheets spectrum with a maximum at $195 \mathrm{~nm}$ and a minimum at $216 \mathrm{~nm} .{ }^{47}$ It was previously reported that twisted $\beta$-sheet structure results in a red-shift in the $\beta$-sheet signal ${ }^{28,48}$ and this shift in CD spectrum depends on twisting degree of $\beta$-sheets. ${ }^{47}$ AIP- $1+2$ consisted of a twisted $\beta$-sheet secondary structure, resulting in such a red shift with a maximum molar ellipticity at around $220 \mathrm{~nm}$ and a minimum at $232 \mathrm{~nm}$ depending on twisting degree of $\beta$-sheets (Figure $3 \mathrm{c}$ ). Similar to AIP- $1+2$, red shift in $\beta$-sheet signal was observed in $\mathrm{pH}$-induced nanofibers of AIP-1 and -2 (Figure S8). In addition to FT-IR and CD analysis, AIP-1 + 2 nanofibers interacted with Congo red, thus, its absorbance shifted from 500 to $530 \mathrm{~nm}$ (Figure 3d). Congo red preferentially intercalated into $\beta$-sheet followed by a shift in its absorbance maxima peak, as demonstrated previously. ${ }^{49,50}$

Viscoelastic Properties of AIP-1 + 2 Gel Concentrations. Amyloid peptide nanostructures are known to have high elastic modulus and mechanical strength due to unique noncovalent organizations of their constituent peptides. ${ }^{1,2}$ We studied mechanical properties of AIP-1 +2 bulk gels and kinetics of gelation using oscillatory rheology in the linear viscoelastic regime (LVR). Storage modulus $\left(G^{\prime}\right)$ is a measure of energy stored as deformation is exerted, while loss modulus $\left(G^{\prime \prime}\right)$ is a measure of energy lost during deformation. As gelation takes place, new elastic chains are produced, resulting in decreased $G^{\prime \prime} / G^{\prime}$ ratio or damping factor. Weak gelation occurred below $2 \%(\mathrm{w} / \mathrm{v})$ AIP-1 + 2 sample (Figure 4a). A significant decrease was observed in the mechanical properties below this concentration (Figure $4 \mathrm{~b})$. Above $2 \%(\mathrm{w} / \mathrm{v})$ concentration, a rapid gelation was recorded within a few seconds of mixing, with equilibrium elastic moduli reaching up to $10^{5}$ $\mathrm{Pa}$. To the best of our knowledge, no other study reported a similar elastic modulus for peptide gels formed solely by self- assembly of synthetic short peptides. Concentration linearly correlated with storage modulus above $2 \%(\mathrm{w} / \mathrm{v})$ concentration (Figure 4c). The linear dependence was due to newly formed elastically active nanofibers participating in gel formation. This was further verified by inverse relationship between damping factor and initial peptide concentration. While the ratio of $G^{\prime \prime} / G^{\prime}$ decreased, elastic modulus exhibited a monotonic increase during concentration sweep, possibly an indication of generating new elastic nanofibers (Figure 4a,d). AIP-1 + 2 gels showed similar gel characteristics at all concentrations above $2 \%(\mathrm{w} / \mathrm{v})$ at both short and long time periods (Figure S9). AIP-1 + 2 gels also exhibited similar recovery behavior after high shear load (Table S2). Thus, the self-assembly mechanism of AIP-1 + 2 nanofibers was similar in different concentrations of the networks.

Comparison of Mechanical Properties of AIP-1, AIP-2, and AIP-1 + 2 gels. To understand superior mechanical properties of AIP-1 + 2 gels, we individually investigated the mechanical properties of its constituent peptides. The $2 \%$ (w/v) AIP-1 gel at $\mathrm{pH} 5$ and AIP-2 gel at $\mathrm{pH} 10$ formed gels via neutralization of their net charges through protonation and deprotonation, respectively. Gelation kinetics showed that AIP$1+2$ gelation rate was slower compared to individual peptide gels (Figure 5a). This was likely due to the presence of attractive and repulsive forces acting in gels of oppositely charged peptides that caused self-assembly and gelation. As charges were neutralized in individual peptide gels, other major acting forces, such as hydrogen bonds and $\pi-\pi$ interactions, stabilized the self-assembly mechanism. On the other hand, in terms of equilibrium modulus, AIP-1 +2 gel was at least an order of magnitude higher than either of the gels of individual peptides (Figure 5b). Here, opposite charges within the network further contributed to the stability of elongating AIP-1 + 2 nanofibers, which accounted for the strong mechanical properties. 

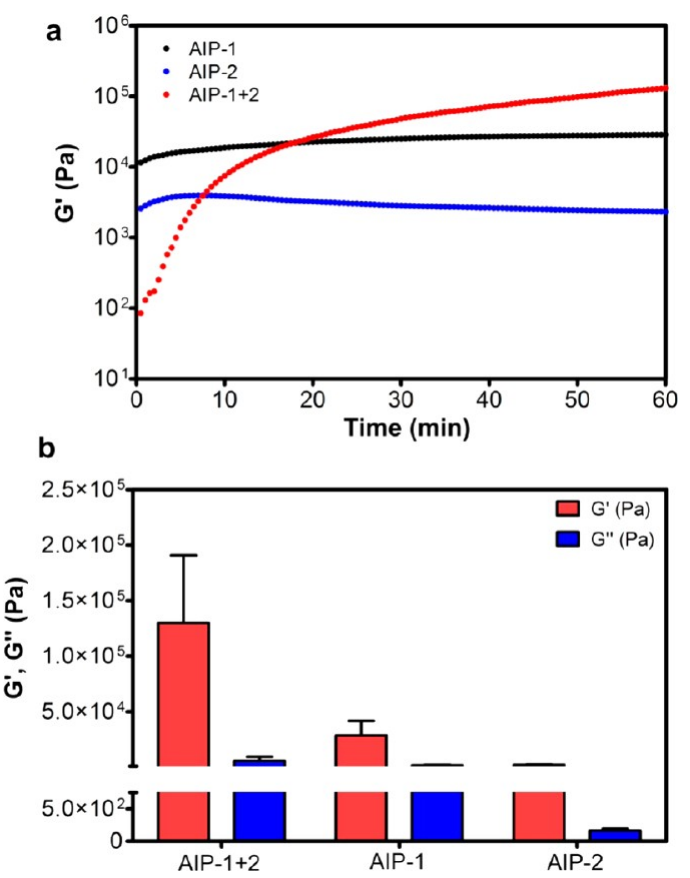

Figure 5. (a) Storage modulus $\left(G^{\prime}\right)$ of AIP-1 +2 , AIP-1, and AIP-2 gels at $\mathrm{pH} \mathrm{7,5}$, and 10, respectively, for $60 \mathrm{~min}$. (b) Equilibrium storage and loss modulus $\left(G^{\prime}, G^{\prime \prime}\right)$ of AIP-1 + 2, AIP-1, and AIP-2 gels at $\mathrm{pH} 7,5$, and 10 , respectively at $60 \mathrm{~min}$.

Nanomechanical Characterization of AIP Nanofibers by AFM. The gels are formed by network of peptide nanofibers, and mechanical properties of the gels are related to the properties of individual nanofibers and their bundles. Strength of both interfiber and intrafiber adhesion is previously shown to be important in determining the mechanical properties of individual nanofibers and their bundles. ${ }^{51}$ Typically, increased adhesion of peptides within the fiber enhances strength and elastic modulus of an individual nanofiber. In addition, increased adhesion between the nanofibers forming a bundle results in improved strength of the bundle and consequently, a more rigid gel. Complementary to rheological measurements on gels, nanomechanical characterizations of AIP-1 + 2, AIP-1, and AIP-2 peptide nanofibers were performed by double-pass force-distance mapping, which allows investigation of the elastic properties at the nanoscale. ${ }^{40}$ Force-distance measurement provides mechanical interaction data for both approach and retraction of the AFM tip. Comparing the approach and retraction curves, structural changes can occur during the nanoindentation experiment. Adhesion and elastic modulus maps of the surfaces carrying peptide nanofibers were generated for data collected during approach (Figure S10) and retraction of the AFM tip (Figures $6 \mathrm{~b}, \mathrm{c}$ and $\mathrm{S} 1 \mathrm{c}-\mathrm{f}$ ). In the maps, monolayer islands of peptides can be resolved on silicon, correlated with similar features in topography (Figures 6 and S11). The visual maps alone do not provide a good insight into the mechanical properties of the nanofibers, and histograms of extracted properties are used to obtain a better comparison.

Adhesion and elasticity (slope) histograms of AIP-1 + 2, AIP-1, and AIP-2 nanofibers (Figure $7 a-d$ ) were collected with similar maximum pressing forces (Figure S13). The slope of the force-distance curves was positively correlated with the elasticity of the nanofibers, which, in turn, was strongly correlated with the strength of bonds between peptides forming the nanofibers. Surfaces containing nanofibers of AIP-1 + 2, AIP-1, and AIP-2 showed elasticity distributions, which can be described by a single peak (Figure 7). The elasticity of undisturbed nanofibers was highest for AIP-1 + 2, AIP-1, and AIP-2 nanofibers, respectively (Figure 7a). During retraction (Figure $7 \mathrm{~b}$ ), AIP-1 and AIP-2 nanofibers showed wider elastic moduli distributions, while the AIP-1 +2 nanofibers continued to display a single peak in the histogram. During approach, the elasticity (slope) can be considered to be of undisturbed nanofibers. The change in the shape of elasticity histograms of AIP-1 and AIP-2 nanofibers was interpreted as a structural change of the nanofiber, possibly due to breaking of bonds within and inbetween nanofibers. The appearance of a tail toward lower elasticity values in the histogram in Figure $7 \mathrm{~b}$ might be due to changes in nanofiber structure, where nanofibers made of AIP-1 and AIP-2 can make a transition from a closed cylindrical shell to a partially or completely ripped shell. In contrast, AIP-1 + 2 nanofibers continued to display a single peaked elasticity distribution. Nanoindentation measurements were performed under relatively small peak forces (on the order of $10 \mathrm{nN}$, see Figure S13). The peak indentation depth can be estimated through the Hertzian contact theory, which gives a value of 2 $\mathrm{nm}$ for a $25 \mathrm{~nm}$ radius tip, for $10 \mathrm{nN}$ applied force. Individual nanofiber diameters are on the order of 5 to $8 \mathrm{~nm}$. The indentation depth is smaller than typical fiber diameter; therefore, thickness of the nanofiber aggregates (up to $40 \mathrm{~nm}$, as seen in Figures 6a and S11a,b) should not play a major role in the observed elastic moduli distributions.

A pronounced difference was also observed in the adhesion force histograms of AIP-1 + 2, AIP-1, and AIP-2 nanofibers (Figure 7c,d). AIP-1 and -2 nanofibers revealed multiple peaks in the approach (Figure 7c), while the AIP-1 + 2 nanofiber exhibited a single peak with increased adhesion force. We believe that AIP-1 and -2 nanofibers have multiple nanoscale
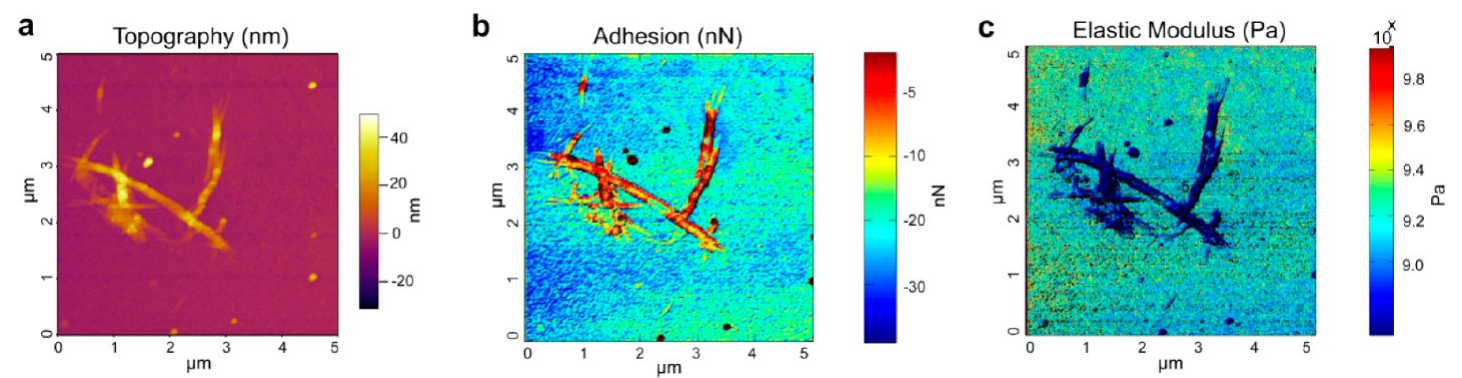

Figure 6. (a) Representative AFM topography image of AIP-1 + 2 nanofiber network on silicon substrate, prepared at pH 7. (b) Adhesion force map of AIP-1 + 2. Data represents maximum adhesion force during retraction. (c) Elastic modulus map of AIP-1 2 calculated from the slope of forcedistance curves (Modulus, Pa). 
a
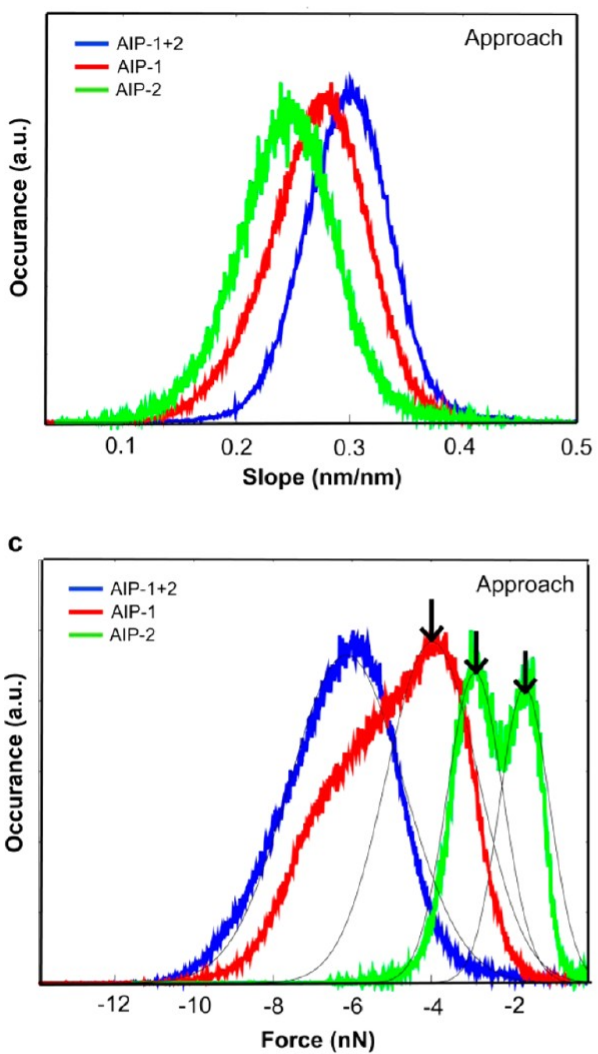

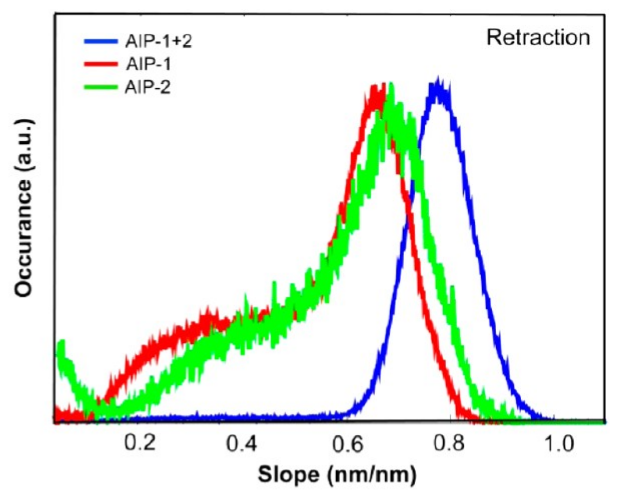

d

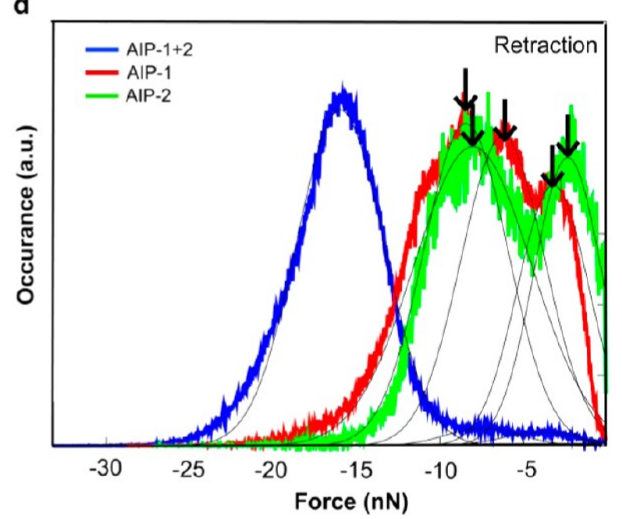

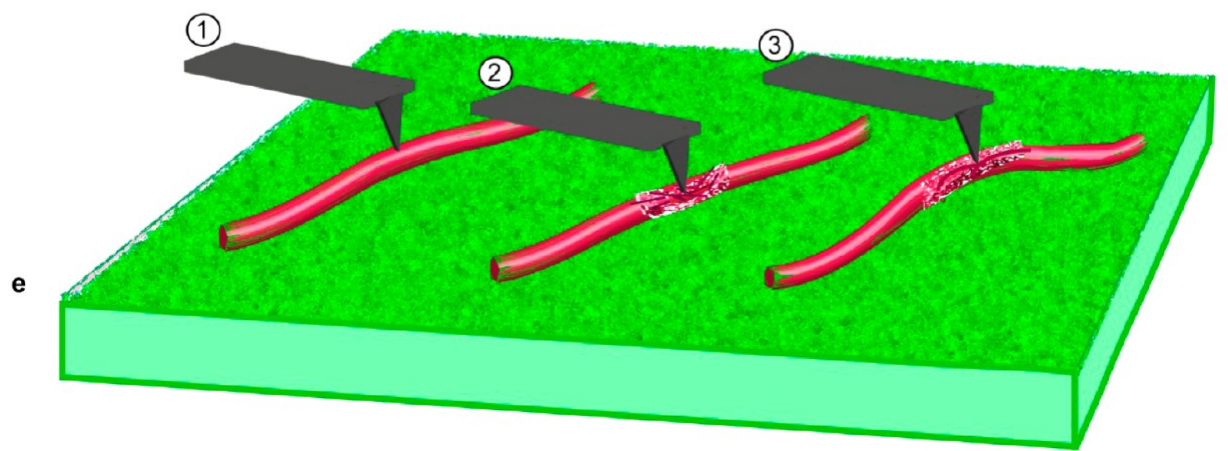

Figure 7. Slope histograms of AIP-1 + 2 at $\mathrm{pH} 7$, AIP-1 at $\mathrm{pH}$ 5, and AIP-2 at $\mathrm{pH} 10$ nanofibers. (a) Approach and (b) retraction of AFM tip. Adhesion force histograms of nanofibers of AIP-1 +2 at $\mathrm{pH} 7$, AIP-1 at $\mathrm{pH} 5$, and AIP-2 at $\mathrm{pH}$ 10, (c) approach and (d) retraction of AFM tip (- Gaussian fittings), (e) schematic representation of nanofiber and AFM tip interactions during nanomechanical characterizations. AIP-1 + 2 nanofibers preserved their shape during approach and retraction of the tip (1). AIP-1 and AIP-2 nanofibers revealed structural change during approach (2) and retraction (3) of the tip.

configurations or exposed sites, where tip interacts. This may be also caused because AIP-1 and -2 nanofibers are not at their minimum energy configuration. The reduced adhesion forces for AIP-1 and -2 as compared to AIP-1 + 2 also showed that AIP-1 + 2 had stronger bonds. Stronger adhesion in AIP-1 + 2 nanofibers was expected to result in greater strength and storage modulus of gels, as observed in macroscopic rheology measurements. Also, comparing the adhesion histograms during approach (Figure 7c) and retraction (Figure 7d), AIP-1 + 2 nanofibers showed a single peak in the adhesion distribution before and after the contact. In contrast, significant changes in the distributions for AIP-1 and -2 nanofibers were observed. Conservation of the single peak for AIP-2 during retraction supported that AIP-1 + 2 nanofibers had greater strength and structural integrity that was conserved during measurements. In the case of AIP-1 and - 2 nanofibers, in retraction (Figure $7 \mathrm{~d}$ ), several well separated peaks was observed in the histograms, pointing to the presence of multiple bonds or binding configurations. Particularly, three peaks were observed in the adhesion histogram of AIP-1 nanofibers separated by about $3 \mathrm{nN}$. Each adhesion peak may correspond to individual peptide interactions. We suggest that self-assembly of oppositely charged peptides at $\mathrm{pH} 7$ had improved adhesion, strength, and stability compared to nanofibers of individual components, which self-assembled by neutralization of the charges at $\mathrm{pH} 5$ and 10. In addition to comparison of the nanofibers and understanding nanomechanical behaviors of AIP-1 + 2 with respect to AIP-1 and AIP-2, we used adhesion and stiffness properties of AIP-1 +2 nanofibers at $\mathrm{pH} 7$ to categorize these nanofibers with respect to other natural proteinaceous 

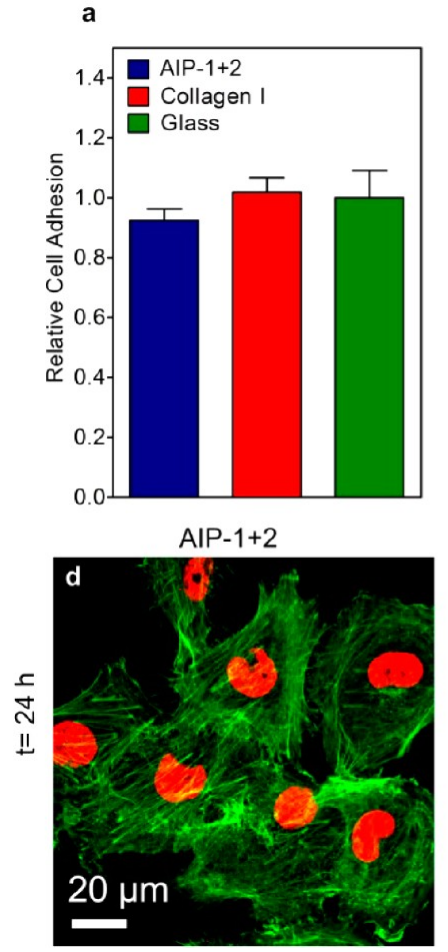

b

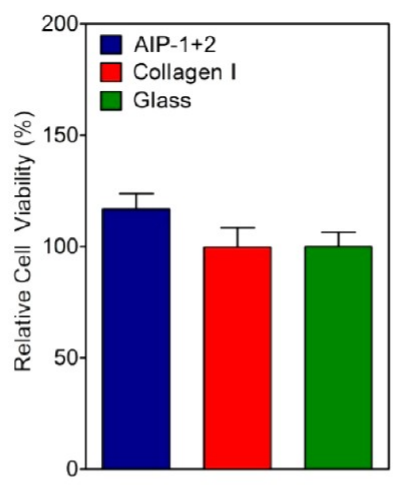

Collagen I

c

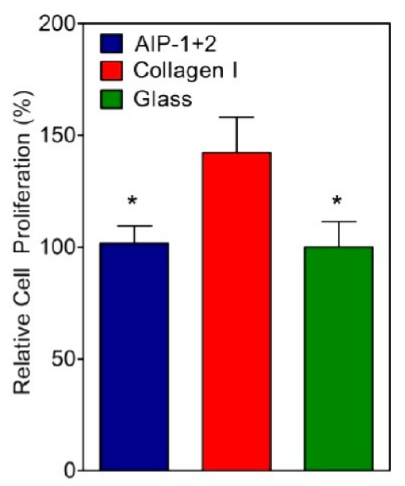

Glass
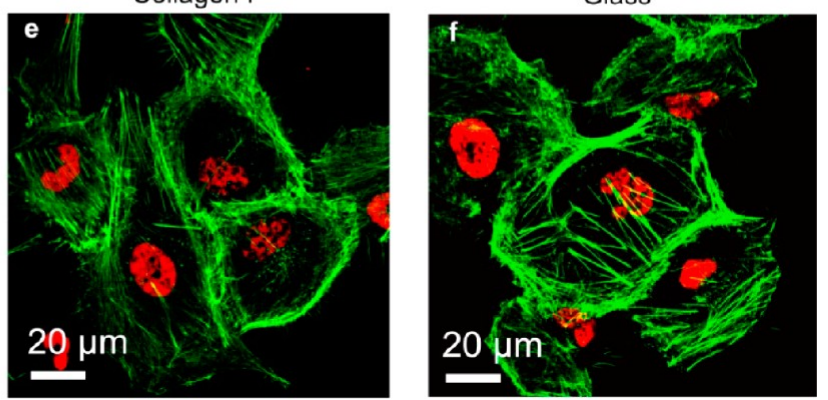

Figure 8. (a) Relative cell adhesion of HUVECs on AIP-1 +2 nanofibers, collagen I covered surfaces, and bare glass after 2 h; (b) Viability of HUVECs on AIP-1 + 2 nanofibers, collagen I covered surfaces, and bare glass after $24 \mathrm{~h}$; (c) Proliferation of HUVECs on AIP-1 + 2 nanofibers, collagen I covered surfaces, and bare glass after $48 \mathrm{~h}$; $(\mathrm{d}-\mathrm{f})$ Confocal images of HUVECs on AIP-1 +2 nanofibers, collagen I coated surfaces, and bare glass after $24 \mathrm{~h}$.

materials. AIP-1 +2 nanofibers revealed stiffness up to $10 \mathrm{GPa}$ (Figure S12), similar to mechanical properties of natural amyloid fibrils and collagen. ${ }^{1}$ Structural modification of the fibers during indentation is schematically shown in Figure 7e.

Cellular Adhesion, Spreading, Viability, and Proliferation on AIP Nanofibers. We exploited AIP-1 + 2 nanofibers for investigation of cell-materials interactions. Cellular adhesion, spreading, viability, and proliferation are critical cellular responses for cell-material interactions. In their native microenvironment, soluble morphogens, extracellular matrix, and direct cell-to-cell contacts regulate cell behavior in a concerted way to determine eventual cell fate. Interfering cellular responses has recently gained tremendous interest as there has been an ever-growing clinical concentration for tissue/organ regeneration and other therapeutic applications. Within this concept, self-assembling peptide nanofibers emerged as useful materials, because their building blocks and amino acids are also the building blocks of life, and synthesis of peptides is relatively convenient and chemically versatile. Conserved short peptide sequences can be readily incorporated into designer systems to provide functionality to the materials to direct cellular behaviors. Thus, we decided to investigate the potential of our system to be used as cell culture scaffolds. Human umbilical vein endothelial cells (HUVECs) were used as model cells because they had previously been used for similar studies. ${ }^{42}$ Adhesion and spreading experiments at $2 \mathrm{~h}$ were carried out under serum-free conditions to avoid the interference of soluble extracellular matrix proteins carrying adhesion signals. To minimize the influence of endogenous proteins on cell adhesion, serum-free medium was supplemented with a translation inhibitor, cyclohexamide. Adhesion test was limited to $2 \mathrm{~h}$ because this time period was previously demonstrated to be sufficient for HUVEC adhesion and spreading in the presence of adhesive signals. ${ }^{42}$ After $2 \mathrm{~h}$, the numbers of adhered cells on AIP- $1+2$ coated, collagen-coated, and uncoated glass surfaces were found to be comparable (Figure 8a). Nonetheless, initial spreading of HUVECs on a collagen-coated glass surface was greater compared to AIP- $1+2$ coated surface and bare glass surface (Figures S14a-c and S15). This significant difference can be attributed to bioactive sequences presented by collagen that can interact with integrin receptors. In addition, even though there was no apparent bioactivity on amyloidinspired peptide nanofibers, the average diameter of cells were longer on AIP- $1+2$ coated surfaces than bare glass surfaces, which could be due to the nanofibrous nature of the coating (Figure S15a). HUVECs attained their native morphology after $24 \mathrm{~h}$ of incubation on peptide nanofiber coated glass as they do on both collagen coated and bare surfaces (Figure $8 \mathrm{~d}-\mathrm{f}$ ). Viability analysis in standard growth medium at $24 \mathrm{~h}$ showed that viability of HUVECs on AIP- $1+2$ peptide nanofibers was comparable to those on collagen coated and bare glass surfaces (Figure 8b). However, HUVECs proliferated at a faster rate on collagen-coated surface compared to both peptide nanofiber coated and bare glass surfaces, as determined from a EdU proliferation assay at $48 \mathrm{~h}$ (Figure $8 \mathrm{c}$ ). The cell proliferation was comparable on glass and AIP-1 +2 nanofibers. Cellular morphology at $48 \mathrm{~h}$ was similar on all surfaces (Figure S14d-f). Overall, the compatibility of the peptide nanofibers was comparable to a natural extracellular matrix component (e.g., collagen). Therefore, AIP-1 +2 nanofibers are considered as biocompatible. Ease of addition of bioactive epitopes on amyloidlike peptide nanofibers and their unique mechanical properties make these scaffolds promising platforms for regenerative medicine studies. 
Encapsulation of a Zwitterionic Dye within AIP-1 + 2 Networks. We also studied encapsulation of a zwitterionic dye, rhodamine B (Rho B), by AIP-1 + 2 peptide gels in order to investigate the encapsulation capability of this system. The dye was introduced to the scaffold before the self-assembly of the AIP-1 and AIP-2 peptides in water at $\mathrm{pH} 7$ to ensure homogeneous dispersion of the dye without damaging the peptide network. In this model, the electrostatic interactions between zwitterionic peptide nanofibers and a zwitterionic dye improved stability of the dye in the system. Different concentrations of AIP-1 + 2 gels showed similar encapsulation properties and kept approximately $94 \%$ of the dye inside the system for $80 \mathrm{~h}$ (Figure S17). Stable encapsulation properties and remarkable mechanical properties of peptide gels exhibit the potential of amyloid peptide nanofibers as carrier systems, which can be functionalized to be used in therapeutic applications.

\section{CONCLUSIONS}

We developed a binary self-assembled peptide nanofiber system inspired by hierarchical self-assembly mechanism of amyloid structures, which demonstrated similar structural and mechanical properties. Understanding interactions that affect the selfassembly mechanisms of peptide nanofibers via computer simulations showed a model for aggregation dynamics of amyloid inspired structures. Characterizations of mechanical properties of the system at bulk gel state and at nanoscale have been performed, revealing improved strength and elastic modulus for amyloid inspired peptide nanofibers. Nanoindentation measurements clearly showed increased resilience and stability of AIP-1 +2 nanofibers under applied pressure by the AFM tip as compared to AIP-1 and AIP-2 nanofibers. Unmatched mechanical properties compared to other synthetic peptide gels, biocompatibility comparable to collagen I, and facile self-assembly mechanism in water at neutral $\mathrm{pH}$ make the amyloid-inspired peptides a suitable platform particularly for biomedical applications.

\section{ASSOCIATED CONTENT}

\section{(S Supporting Information}

LC-MS results; TEM and SEM images of peptide nanofibers; snapshots of simulation; simulation results based on noncovalent interactions between the peptides, DSSP analysis, FT$\mathrm{IR}, \mathrm{CD}$, frequency, and thixotropic test results of the gels, topography, adhesion, elastic modulus maps, and histograms of nanomechanical characterizations; and confocal images of HUVECs after 2 and $48 \mathrm{~h}$. This material is available free of charge via the Internet at http://pubs.acs.org.

\section{AUTHOR INFORMATION}

\section{Corresponding Author}

*E-mail: moguler@unam.bilkent.edu.tr (M.O.G); aykutlu@ unam.bilkent.edu.tr (A.D.); atekinay@unam.bilkent.edu.tr (A.B.T.); edtekin@thk.edu.tr (E.D.T.).

\section{Notes}

The authors declare no competing financial interest.

\section{ACKNOWLEDGMENTS}

Numerical calculations were performed at TUBITAK ULAKBIM High Performance and Grid Computing Center (TRUBA Resources). This work was partially funded by TUBITAK 109T603, 112T452, and FP7 Marie Curie International Reintegration Grant. H.C. is supported by TUBITAK-BIDEB $\mathrm{PhD}$ fellowship. M.O.G. acknowledges support from the
Turkish Academy of Sciences Distinguished Young Scientist Award (TUBA-GEBIP).

\section{REFERENCES}

(1) Knowles, T. P. J.; Buehler, M. J. Nat. Nanotechnol. 2011, 6, 469479.

(2) Chiti, F.; Dobson, C. M. Annu. Rev. Biochem. 2006, 75, 333-366.

(3) Kelly, J. W.; Balch, W. E. J. Cell Biol. 2003, 161, 461-462.

(4) Sunde, M.; Serpell, L. C.; Bartlam, M.; Fraser, P. E.; Pepys, M. B.; Blake, C. C. F. J. Mol. Biol. 1997, 273, 729-739.

(5) Liang, Y.; Lynn, D. G.; Berland, K. M. J. Am. Chem. Soc. 2010, 132, 6306-6308.

(6) Ban, T.; Hoshino, M.; Takahashi, S.; Hamada, D.; Hasegawa, K.; Naiki, H.; Goto, Y. J. Mol. Biol. 2004, 344, 757-767.

(7) Xu, S. J. Phys. Chem. B 2009, 113, 12447-12455.

(8) Makin, O. S.; Atkins, E.; Sikorski, P.; Johansson, J.; Serpell, L. C. Proc. Natl. Acad. Sci. U.S.A. 2005, 102, 315-320.

(9) Sweers, K.; van der Werf, K.; Bennink, M.; Subramaniam, V. Nanoscale Res. Lett. 2011, 6, 1-10.

(10) Paparcone, R.; Keten, S.; Buehler, M. J. J. Biomech. 2010, 43, 1196-1201.

(11) Guo, S.; Akhremitchev, B. B. Biomacromolecules 2006, 7, 16301636.

(12) Kurland, N. E.; Drira, Z.; Yadavalli, V. K. Micron 2011, 43, 116128.

(13) Brubaker, C. E.; Messersmith, P. B. Langmuir 2012, 28, 22002205.

(14) Wiradharma, N.; Khan, M.; Tong, Y. W.; Wang, S.; Yang, Y. Y. Adv. Funct. Mater. 2008, 18, 943-951.

(15) Bulut, S.; Erkal, T. S.; Toksoz, S.; Tekinay, A. B.; Tekinay, T.; Guler, M. O. Biomacromolecules 2011, 12, 3007-3014.

(16) Renggli, K.; Baumann, P.; Langowska, K.; Onaca, O.; Bruns, N.; Meier, W. Adv. Funct. Mater. 2011, 21, 1241-1259.

(17) Ellis-Behnke, R. G.; Liang, Y. X.; You, S. W.; Tay, D. K. C.; Zhang, S.; So, K. F.; Schneider, G. E. Proc. Natl. Acad. Sci. U.S.A. 2006, 103, 5054-5059.

(18) Zhao, X.; Pan, F.; Xu, H.; Yaseen, M.; Shan, H.; Hauser, C. A. E.; Zhang, S.; Lu, J. R. Chem. Soc. Rev. 2010, 39, 3480-3498.

(19) De La Rica, R.; Matsui, H. Chem. Soc. Rev. 2010, 39, 34993509.

(20) Toksoz, S.; Acar, H.; Guler, M. O. Soft Matter 2010, 6, 58395849.

(21) Jahn, T. R.; Makin, O. S.; Morris, K. L.; Marshall, K. E.; Tian, P.; Sikorski, P.; Serpell, L. C. J. Mol. Biol. 2010, 395, 717-727.

(22) Ryan, D. M.; Nilsson, B. L. Polym. Chem. 2012, 3, 18-33.

(23) Thomas, A.; Meurisse, R.; Charloteaux, B.; Brasseur, R. Proteins: Struct., Funct., Bioinf. 2002, 48, 628-634.

(24) Gazit, E. FASEB J. 2002, 16, 77-83.

(25) Lazo, N. D.; Grant, M. A.; Condron, M. C.; Rigby, A. C.; Teplow, D. B. Protein Sci. 2005, 14, 1581-1596.

(26) Roychaudhuri, R.; Yang, M.; Hoshi, M. M.; Teplow, D. B. J. Biol. Chem. 2009, 284, 4749-4753.

(27) Altunbas, A.; Sharma, N.; Lamm, M. S.; Yan, C.; Nagarkar, R. P.; Schneider, J. P.; Pochan, D. J. ACS Nano 2009, 4, 181-188.

(28) Acar, H.; Garifullin, R.; Guler, M. O. Langmuir 2011, 27, 10791084.

(29) Thompson, M. A.; Zerner, M. C. J. Am. Chem. Soc. 1991, 113, $8210-8215$

(30) Oostenbrink, C.; Villa, A.; Mark, A. E.; Van Gunsteren, W. F. J. Comput. Chem. 2004, 25, 1656-1676.

(31) Van Der Spoel, D.; Lindahl, E.; Hess, B.; Groenhof, G.; Mark, A. E.; Berendsen, H. J. C. J. Comput. Chem. 2005, 26, 1701-1718.

(32) Smith, P. E.; van Gunsteren, W. F. Chem. Phys. Lett. 1993, 215, 315-318.

(33) Hockney, R.; Goel, S.; Eastwood, J. J. Comput. Phys. 1974, 14, $148-158$.

(34) Hess, B.; Bekker, H.; Berendsen, H. J. C.; Fraaije, J. G. E. M. J. Comput. Chem. 1997, 18, 1463-1472. 
(35) Darden, T.; York, D.; Pedersen, L. J. Chem. Phys. 1993, 98, 10089-10092.

(36) Essmann, U.; Perera, L.; Berkowitz, M. L.; Darden, T.; Lee, H.; Pedersen, L. G. J. Chem. Phys. 1995, 103, 8577-8593.

(37) Parrinello, M.; Rahman, A. J. Appl. Phys. 1981, 52, 7182-7190.

(38) Bussi, G.; Donadio, D.; Parrinello, M. J. Chem. Phys. 2007, 126, 014101-014107.

(39) Humphrey, W.; Dalke, A.; Schulten, K. J. Mol. Graphics 1996, $14,33-38$.

(40) Dagdas, Y. S.; Necip Aslan, M.; Tekinay, A. B.; Guler, M. O.; Dâna, A. Nanotechnology 2011, 22, 295704.

(41) Baudin, B.; Bruneel, A.; Bosselut, N.; Vaubourdolle, M. Nat. Protoc. 2007, 2, 481-485.

(42) Ceylan, H.; Tekinay, A. B.; Guler, M. O. Biomaterials 2011, 32, $8797-8805$.

(43) Kabsch, W.; Sander, C. Biopolymers 1983, 22, 2577-2637.

(44) Hiramatsu, H.; Kitagawa, T. Biochim. Biophys. Acta, Proteins Proteomics 2005, 1753, 100-107.

(45) Zandomeneghi, G.; Krebs, M. R. H.; McCammon, M. G.; Fändrich, M. Protein Sci. 2004, 13, 3314-3321.

(46) Hiramatsu, H.; Goto, Y.; Naiki, H.; Kitagawa, T. J. Am. Chem. Soc. 2004, 126, 3008-3009.

(47) Kubelka, J.; Keiderling, T. A. J. Am. Chem. Soc. 2001, 123, 12048-12058.

(48) Pashuck, E. T.; Cui, H.; Stupp, S. I. J. Am. Chem. Soc. 2010, 132, 6041-6046.

(49) Carter, D.; Chou, K. C. Neurobiol. Aging 1998, 19, 37-40.

(50) Liang, G.; Xu, K.; Li, L.; Wang, L.; Kuang, Y.; Yang, Z.; Xu, B. Chem. Commun. 2007, 4096-4098.

(51) Dagdas, Y. S.; Tombuloglu, A.; Tekinay, A. B.; Dana, A.; Guler, M. O. Soft Matter 2011, 7, 3524-3532. 